\title{
Monitoring urban land surface deformation (2004-2010) from InSAR, groundwater and levelling data: A case study of Changzhou city, China
}

\author{
Yan-Yan Lu ${ }^{1,2}$, Chang-Qing $\mathrm{KE}^{2}$,* Hou-Jun Jiang ${ }^{3}$ and De-Liang Chen ${ }^{3}$ \\ ${ }^{1}$ Research Academy of Natural Resources and Environment Audit, Nanjing Audit University, Nanjing 211 815, \\ People's Republic of China. \\ ${ }^{2}$ School of Geography and Ocean Science, Jiangsu Provincial Key Laboratory of Geographic Information Science \\ and Technology, Key Laboratory for Satellite Mapping Technology and Applications of State Administration of \\ Surveying, Mapping and Geoinformation of China, Nanjing University, Nanjing 210 023, \\ People's Republic of China. \\ ${ }^{3}$ College of Geographic and Biologic Information, Nanjing University of Posts and Telecommunications, \\ Nanjing 210 023, People's Republic of China. \\ *Corresponding author. e-mail: kecq@nju.edu.cn
}

MS received 25 October 2016; revised 19 July 2018; accepted 9 March 2019; published online 4 June 2019

Land deformation caused by the overexploitation of groundwater has become a potential geological hazard in Changzhou, China. To reduce the potential damage from deformation disasters, it is quite necessary to monitor them. In this study, C-band ENVISAT ASAR synthetic aperture radar (SAR) datasets acquired from 2004 to 2010 were processed with the small baseline subset (SBAS) interferometric SAR (InSAR) method to investigate the spatial-temporal distribution of land deformation. Levelling survey data were used to assess the deformation accuracy measured by the InSAR method, and groundwater level data were used to analyse the incentives for deformation. The SBAS InSAR results found several subsidence regions in the Wujin district and the central part of the Zhonglou district. The annual deformation rate calculated from the C-band interferograms ranged from -65 to $+35 \mathrm{~mm} / \mathrm{yr}$ in the line of sight (LOS) direction, and the cumulative subsidence ranged from -0.35 to $0.13 \mathrm{~m}$ in the vertical direction. The levelling survey data show that the two measurements are generally consistent. Correlation analysis between the groundwater table and InSAR measurements at six groundwater well stations shows that groundwater recharges can cause land rebound within the Changzhou urban region. However, subsidence was also observed simultaneously with a rising water table, which might have been caused by the status of consolidation of the strata. Our study provides scientific evidence on the management of groundwater extraction and the assessment of land-subsidence hazard.

Keywords. Changzhou; land deformation; SBAS InSAR; groundwater.

\section{Introduction}

Human activities that excessively exploit groundwater give rise to areas with serious land deformations worldwide (Baek et al. 2008; Conway
2015; Faunt et al. 2015; Castellazzi et al. 2016; Hwang et al. 2016; Notti et al. 2016). In urban areas, land deformation can result in extensive damage to infrastructure such as highways, bridges, 
buildings, pipelines and subways (Ma et al. 2010; Dong et al. (2014); Chaussard et al. 2014; Brunori et al. 2015). In coastal cities, land subsidence increases the risks of flooding and seawater intrusion (Abidin et al. 2013; Hallegatte et al. 2013; Conway 2015).

Changzhou, an emerging city in China, has suffered from serious land deformation since the 1960s (Wang et al. 2009). In 1990, the deformation rate reached $109 \mathrm{~mm} / \mathrm{yr}$ (Zhang et al. 2010). To control the land subsidence, in the late 1990s, the Changzhou city government instituted measures such as prohibiting groundwater exploitation in the urban areas of the city (Xie et al. 2009). At the beginning of the 20th century, the China Geological Survey deployed a project named 'Investigation and monitoring of ground settlement in the Yangtze river delta area', in which variations of land deformation in Changzhou are monitored using the global positioning system (GPS), levelling surveys and water-level gauges survey method (Zhu and Liu 2007; Hu 2011). These conventional deformation-monitoring techniques provided robust monitoring of land deformation, but were unable to detect spatial details and comprehensive information about land deformation due to their low spatial resolution and small area coverage. To monitor the evolution of deformation spatially and temporally in Changzhou, interferometric SAR (InSAR) technology can be used.

InSAR is an advanced remote sensing technology developed over the past few decades. InSAR has proved to be an invaluable technique for measuring land deformations over large areas due to its high spatial resolution and sub-centimetre accuracy (Bürgmann et al. 2000; Wang et al. 2004, 2012; Akcin et al. 2010; Hu et al. 2014). Traditional DInSAR (differential InSAR) method focuses on a single pair of InSAR images to detect deformations; however, factors such as temporal/spatial decoherence and atmospheric phase interference often affect the formation of interferograms. To overcome these problems, advanced DInSAR technologies such as permanent scatterers (PS) InSAR (Ferretti et al. 2000, 2001) and small baseline subset (SBAS) InSAR (Berardino et al. 2002; Lanari et al. 2004, 2007) have been developed. These two methods are designed to identify and quantify the millimetre-level movements of natural features (such as bare rock outcrops and boulders) and manmade structures (such as buildings, highwayrelated objects and artificial corner reflector) in an area. The sizes of these reflecting objects are usually smaller than a resolution cell, and the coherence of these objects remains high. In the PS InSAR method, image pixels are identified in a stack of interferograms generated with a single master scene. These interferograms are analysed at a single look resolution to maximise a signalto-clutter ratio of resolution cells containing a single dominant scatterer (Ferretti et al. 2001). The SBAS InSAR method derives the deformation signal from multi-looked interferograms with most highly correlated areas, and this method reduces speckle and improves the phase estimate. Moreover, the SBAS InSAR method limits the effects of spatial and temporal decoherence with a short spatial baseline and can identify individual phase-coherence pixels surrounded by completely decorrelated pixels (Berardino et al. 2002; Shanker 2011).

Each of these two methods has its advantages and they have both proved to be effective in monitoring land deformation in Changzhou city. In 2015, Ding et al. (2015) used PS InSAR with TerraSAR-X data to address land deformation that occurred from 2011 to 2013. Zhang (2016) applied the PS-InSAR technique to 28 ENVISAT ASAR data to address land deformation in the Wujin district in Changzhou that occurred between 2006 and 2010 (Zhang 2016). Remarkably, however, Ding et al. (2015) and Zhang (2016) did not discuss the relationship between groundwater extraction and land deformation. Lin and Ke (2016) studied land surface deformation with COSOMO-SkyMed data over the period from 2011 to 2012, but the short time span prohibited a more detailed analysis of land deformation. To obtain more comprehensive information about land deformation and examine the relationship between groundwater extraction and land deformation over a long period, more data and advanced InSAR processing approaches are needed.

In this paper, considering the SBAS InSAR method performed better than the PS InSAR method with respect to the aspects of analysing the nonlinear displacement rate and reducing the effects of spatial and temporal decorrelation (Lauknes et al. 2010; Shanker et al. 2011; Necsoiu et al. 2014), we used the SBAS InSAR technology with data from ENVISAT ASAR (acquired from 2004 to 2010) to investigate the spatial and temporal land deformation over Changzhou city, China. Levelling measurements are used to assess the accuracy of the InSAR result. The correlations between the InSAR time-series measurements 
and groundwater table change are analysed to investigate the interaction between land subsidence and groundwater exploitation.

\section{Study area and datasets}

\subsection{Study area}

Changzhou city is located in the South of Jiangsu Province, China, bordered by the Yangtze river to the north and Tai lake to the south. Its geographic location is $31^{\circ} 09^{\prime}-32^{\circ} 04^{\prime} \mathrm{N}$ and $119^{\circ} 08^{\prime}-120^{\circ} 12^{\prime} \mathrm{E}$; the cities of Suzhou and Wuxi are toward the east. The total area of Changzhou is approximately $4385 \mathrm{~km}^{2}$, and the major region of Changzhou contains the Xinbei, Zhonglou, Tianning and Wujin districts (figure 1). The Changzhou region is characterised by a tremendous range of geological structures and a sophisticated genesis of Quaternary sediments. This city area is also manifested land deformation by the development of multiple sand aquifers and soft clay layers (Wang et al. 2009; Zhang et al. 2010; Xu et al. 2015). Consequently, the region has been bestowed with abundant groundwater throughout various geological historical stages.

As an important part of the Su-Xi-Chang area (including Suzhou, Wuxi and Changzhou) and the heartland of the Yangtze river delta, the urbanisation of Changzhou has proceeded quickly. According to a report from the Statistics Bureau of
Jiangsu Province, the urbanised area of Changzhou had reached $68.70 \%$ by the end of 2014, and the population of Changzhou increased from 3.41 million in 2002 to 4.69 million in 2014. This rapid urbanisation and population growth has been accompanied by a corresponding increase in the demand for industrial and domestic water. Meanwhile, surface water pollution from urbanisation has also increased the pressures on the water supply. Therefore, a large amount of groundwater is extracted to meet the demand for water. Excessive exploitation of groundwater from the aquifers caused the consolidation of sedimentary deposits and, finally, resulted in the land deformations in this area.

\subsection{SAR data}

The input data for SBAS InSAR in this study were collected from ENVISAT Advanced InSAR (ASAR) images from the European Space Agency (ESA). ASAR operates in the $\mathrm{C}$ band in a wide variety of modes (such as alternating polarisation, image, wave, global monitoring and wide swath) (table 1). The image mode is widely used in InSAR processing, and this mode is very useful in getting the land deformation with sub-millimetre precision. The image mode of ASAR is used to monitor land deformation over large areas, because this mode can provide a large coverage of $100 \times$ $100 \mathrm{~km}^{2}$. Moreover, the microwaves of the ASAR

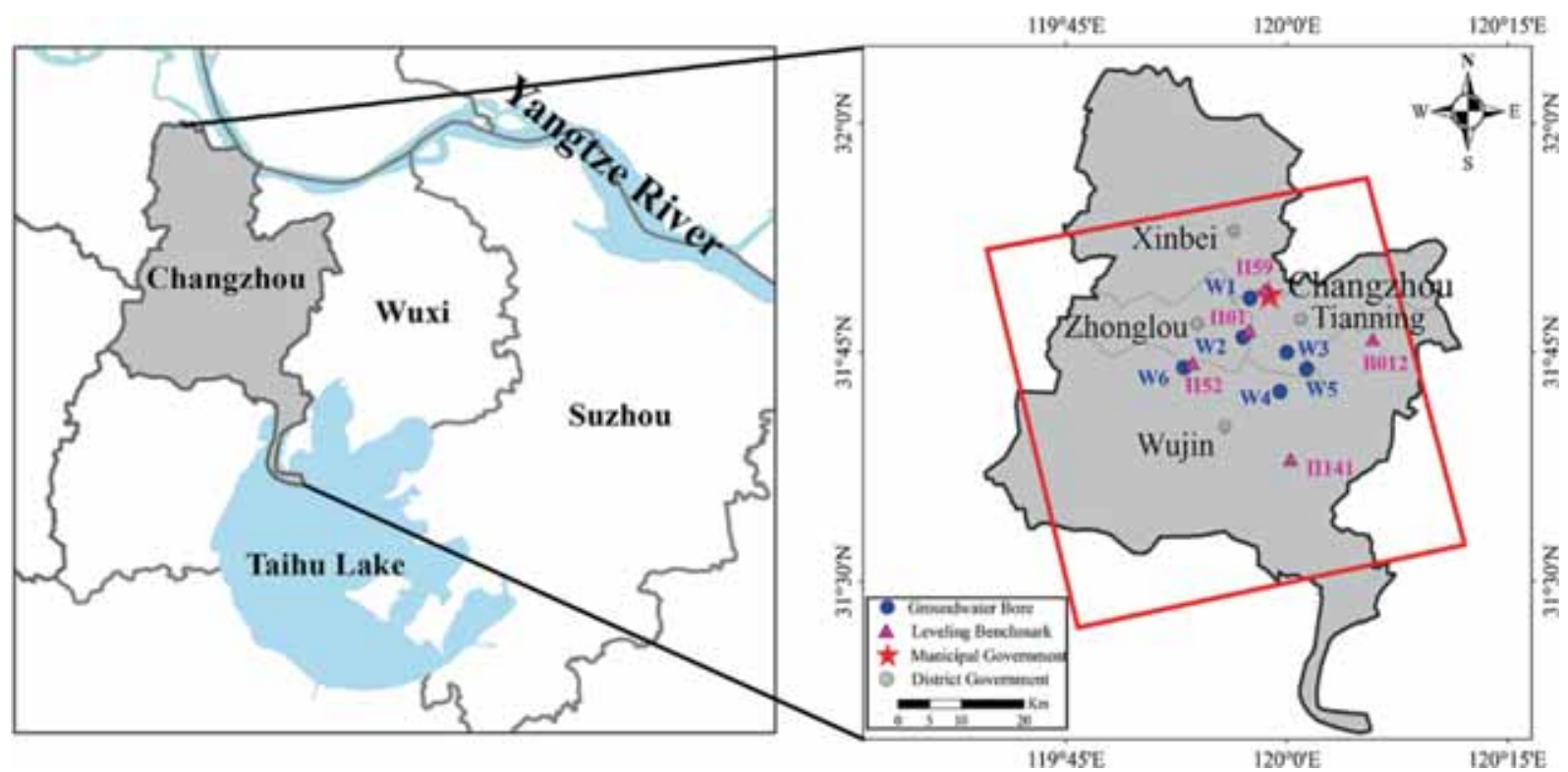

Figure 1. Geographical location of Changzhou city, China. The red polygon represents the study area. The right panel also shows the distribution of groundwater wells and levelling stations used in this study. The names of the levelling stations are indicated by the purple letters. A groundwater well is labelled with "W" followed by a number. 
Table 1. Summary information of ENVISAT ASAR.

\begin{tabular}{lccccc}
\hline Mode & $\begin{array}{c}\text { Alternating } \\
\text { polarisation }\end{array}$ & Image & Wave & $\begin{array}{c}\text { Suivi } \\
\text { global }\end{array}$ & $\begin{array}{c}\text { Wide } \\
\text { Swath }\end{array}$ \\
\hline Polarisation & $\mathrm{HH} / \mathrm{VV}, \mathrm{HH} / \mathrm{HV}, \mathrm{VV} / \mathrm{VH}$ & $\mathrm{HH}, \mathrm{VV}$ & $\mathrm{HH}, \mathrm{VV}$ & $\mathrm{HH}, \mathrm{VV}$ & $\mathrm{HH}, \mathrm{VV}$ \\
Incidence $(\mathrm{deg})$ & $15-45$ & $15-45$ & $15-45$ & $15-45$ & $15-45$ \\
Resolution $(\mathrm{m})$ & $30-150$ & $30-150$ & 400 & 1000 & 150 \\
Swath $(\mathrm{km})$ & $58-110$ & $58-110$ & 5 & 400 & 400 \\
\hline
\end{tabular}

Table 2. ENVISAT ASAR dataset information used in this study.

\begin{tabular}{lccccccr}
\hline Band & $\begin{array}{c}\text { Wavelength } \\
(\mathrm{cm})\end{array}$ & $\begin{array}{c}\text { Heading } \\
(\mathrm{deg})\end{array}$ & $\begin{array}{c}\text { Incidence } \\
\text { angle }(\mathrm{deg})\end{array}$ & Polarisation & $\begin{array}{c}\text { Orbit } \\
\text { type }\end{array}$ & $\begin{array}{c}\text { No. of } \\
\text { images }\end{array}$ & Data range \\
\hline $\mathrm{C}$ & 5.6 & -11.93 & 22.79 & $\mathrm{VV}$ & Ascending & 36 & $\begin{array}{c}20-\text { May-04 to } \\
29-\text { Apr-10 }\end{array}$ \\
\hline
\end{tabular}

image mode dataset have longer wavelengths than infrared and visible EM radiation that allow them to penetrate fog and clouds. This unique property allows ASAR to provide imagery with less interference from the weather than the infrared and visible EM radiation during the land surface deformation monitoring. Our study area is characterised by a northern subtropical marine climate that features plentiful rain; this feature makes C-band ASAR data (which is unaffected by weather conditions) more suitable for land subsidence analysis (Curlander and Mcdonough 1991). The flat-earth phase which is produced by the flat terrain increases the difficulty of InSAR phase unwrapping and severely degrades the accuracy of deformation monitoring (Kimura and Todo 1997); however, when the satellite orbit data are known, the flat-earth phase can be accurately calculated and removed. The C-band ENVISAT ASAR data use the precise satellite orbit data provided by the Delft Institute of Earth Observation and Space Systems (DEOS) to remove the flat-earth phase in InSAR processing (Kohlhase et al. 2003). In contrast, for L-band ALOS data and X-band data (such as COSMO-Skymed data), acquiring precise satellite orbit data such as that provided by DEOS is impossible. Changzhou's geomorphological type is alluvial plain, which is seriously affected by the flat-earth phase; consequently, the C-band ENVISAT ASAR data with satellite orbit data provided by DEOS is more suitable for monitoring land subsidence in this area. Unfortunately, ESA announced that ASAR lost contact with ENVISAT on April 2012. In this study, we acquired 36 SAR images from the C-band ENVISAT ASAR that covered the study area before 2012 (table 2). All images used in this study were taken with $\mathrm{VV}$ polarisation and from the ascending orbit.

\subsection{Shuttle radar topography mission (SRTM) digital elevation model (DEM)}

The SRTM was a NASA mission conducted in 2000 to obtain elevation data for most of the world. The DEM data provided by SRTM satisfied the demand of InSAR processing with a fairly high resolution (about $90 \mathrm{~m}$ ) and near-global coverage (from $56^{\circ} \mathrm{S}$ to $60^{\circ} \mathrm{N}$ ). The SRTM DEM data were publicly released in 2003 and have been revised many times. SRTM DEM was used in this study to remove the topographic contribution to the interferometric phase (Rabus et al. 2003).

\subsection{Levelling data}

To understand the status of land deformation in Changzhou, the government has undertaken levelling measurements for many years. Levelling data covering the period from 2006 to 2012 acquired from five levelling monitoring sites was provided by Changzhou Surveying and Mapping Institute and used to verify the precision of the InSAR measurements (figure 1).

\subsection{Groundwater data}

In Changzhou, the main layer involved in groundwater extraction is the second aquifer. To explore the relationship between variations in the water table and land deformation, groundwater table data of the second aquifer obtained from six water wells were used in this study (labelled as 
W1-W6 in figure 1). These data were provided by the Jiangsu Province Hydrology and Water Resources Investigation Bureau.

\section{Method}

\subsection{SBAS-InSAR principles}

SBAS-InSAR is a newly developed DInSAR-based time-series analysis method that was first proposed (Berardino et al. 2002). Over the past decade, the SBAS algorithm has been continually improved and has been widely used in surface deformation studies (Berardino et al. 2002; Lanari et al. 2004, 2007; Baek et al. 2008; Zhao et al. 2012; Chaussard et al. 2014). During SBAS-InSAR processing, all SAR images are subject to random combinations and form interference pairs.

Assume that $N+1$ SAR images exist covering the same area with acquisition times of $t_{0}, t_{1}, \ldots, t_{N}$ and that an image from each scene can form an interference pair with at least one image of another scene. The SAR images whose vertical baselines are below the threshold of the small baseline condition are grouped together to generate a total of $L$ candidate images and $M$ differential interferograms, where $M$ satisfies the following inequality (assuming $N$ is an odd number) (Berardino et al. 2002; Lanari et al. 2004, 2007):

$$
\frac{N+1}{2} \leq M \leq N\left(\frac{N+1}{2}\right)
$$

If all of the differential interferograms are correctly unwrapped, they can be calibrated by a highly coherent point $\left(x_{0}, r_{0}\right)$ that is stable or whose deformation magnitude is known. For a specific interferogram (i.e., after the removal of the flat earth and topographic phases), assume that $t_{\mathrm{B}}>t_{\mathrm{A}}$ (where $t_{\mathrm{A}}$ and $t_{\mathrm{B}}$ are the two acquisition dates of the co-registered image pair for the interferogram $i$ ). Then, in a coordinate system of azimuth-range $(x, r)$, the interferometric phase of a pixel $(x, r)$ in the differential interferogram $i$ can be expressed as follows (Lanari et al. 2007):

$$
\begin{aligned}
& \delta \phi_{i}(x, r)=\phi\left(t_{\mathrm{B}}, x, r\right)-\phi\left(t_{\mathrm{A}}, x, r\right) \\
& \approx \frac{4 \pi}{\lambda}\left[d\left(t_{\mathrm{B}}, x, r\right)-d\left(t_{\mathrm{A}}, x, r\right)\right]+\frac{4 \pi}{\lambda} \times \frac{B_{\perp i} \Delta Z}{r \sin \theta} \\
& \quad+\left[\phi_{\mathrm{atm}}\left(t_{\mathrm{B}}, x, r\right)-\phi_{\mathrm{atm}}\left(t_{\mathrm{A}}, x, r\right)\right]+\Delta \phi, \quad(2
\end{aligned}
$$

where $\lambda$ is the centre wavelength of the imaging radar system and $d\left(t_{\mathrm{B}}, x, r\right)$ and $d\left(t_{\mathrm{A}}, x, r\right)$ represent the relative displacements in the direction of the radar line of sight (LOS) at times $t_{\mathrm{B}}$ and $t_{\mathrm{A}}$, respectively. Here, $\left(B_{\perp i} \Delta Z\right) /(r \sin \theta)$ is the phase resulting from the DEM (or height) error $\Delta Z$ and the vertical component $B_{\perp i}$ of the baseline orbit separation between the SAR image pair; its value is directly proportional to $B_{\perp i}$ and inversely proportional to the slant range $r$, and it is associated with the local incidence angle $\theta$. The term $\left[\phi_{\mathrm{atm}}\left(t_{\mathrm{B}}, x, r\right)-\phi_{\mathrm{atm}}\left(t_{\mathrm{A}}, x, r\right)\right]$ is the difference between the atmospheric delay phases of pixel $(x, r)$ at times $t_{\mathrm{A}}$ and $t_{\mathrm{B}}$, and $\Delta \phi$ represents other noises.

After phase unwrapping, the linear deformation and DEM error phase can be used to construct a new SBAS linear equation (Hallegatte et al. 2013):

$$
[B, C] p^{\prime}=\delta \phi
$$

where $B$ is an $M \times N$ matrix, and $C$ is the coefficient matrix related to the space-baseline distance. The value $p^{\prime}$ is given by

$$
p^{\prime}=\left[\begin{array}{ll}
v & \Delta Z
\end{array}\right]^{\mathrm{T}},
$$

where $v$ represents the phase-value matrix of the average deformation rate.

The linear deformation phase and DEM errors are removed from the interferogram to generate the residual phases, which now include the atmospheric delay phase, nonlinear deformation phase and decoherence noises. Subsequently, filtering is performed based on the different temporal and spatial properties of the residual phases, thereby separating the nonlinear deformation phase and atmospheric delay phase. Finally, time-series deformation results can be obtained by applying a least squares (LS) method (Usai 2003) or singular value decomposition (SVD) rule (Costantini 1998) to all the unwrapped interferograms.

\subsection{SBAS-InSAR processing}

SBAS-InSAR can divide the whole SAR dataset available into different subsets. Interference pairs were made by multiplying a master complex image with a conjugate of a slave complex SAR image in every subset according to the following principle: within each subset, the spatial-temporal baseline was smaller than a threshold defined by the user, 
but between subsets, the baseline was relatively larger. The purpose of such an approach was to mitigate both spatial and temporal decorrelations and to preserve high interferometric coherence.

In this study, we set the threshold of the spatial baseline to $<400 \mathrm{~m}$ and the temporal baseline to $<400$ days. To dampen the noises, boost coherence and examine the deformation at a relatively large scale, interferograms are subject to a multi-look treatment using five azimuth looks and one range look. Thus, a total of 152 interferometry pairs (or interferograms) are constructed. We also get the relationship between the temporal and perpendicular baselines of InSAR interferograms (figure 2). As these interferograms were influenced by strong orbit error, flat-earth phase, topographic phase, interferometric noise and atmospheric phase, the effective deformation information could not be obtained. Six representative interferograms were shown in figure 3 and these pictures were the comprehensive effect of a strong orbit error, flat-earth phase, topographic phase, interferometric noise and atmospheric phase. Strong residual phase ramp originating from the orbit error, together with a large atmospheric pattern can be observed in figure 3(b, d and e) obviously. Large residual fringes remain caused by atmospheric artefacts together with a small ramp caused by orbit inaccuracies can be observed in figure 3(a and c) obviously. Interferometric noise and atmospheric patterns can be observed in figure 3(f) obviously. DEOS precise orbit dataset are used to remove orbit error and the flat-earth phase. SRTM DEM data are used to remove the topographic phase. The adaptive spectral filtering method is employed to suppress the interferometric noise. After completing the above operations, the minimum cost flow (MCF) method (Costantini 1998), which is integrated with a region growing procedure to improve the performance in areas with low signal-to-noise ratios, is used to unwrap the complex phase over the Changzhou area. The coherent pixel (CP) candidates are characterised by high average spatial coherence. In this study, we retained the CP points with a high value of 0.85 as the reference points during the unwrapping process.

Through the above processing steps, we obtained unwrapped interferograms. The core of the SBAS is the inversion of unwrapped interferograms for the retrieval of time-series deformation. First, a LS approach was used to determine every small subset deformation. Secondly, SVD was used to merge these small subset results (Berardino et al. 2002). The deformation results include an atmospheric phase that should be detected and removed. Because the atmospheric phase signals are highly correlated in space but poorly correlated in time, the following method is used to estimate and remove the atmospheric delay phase: low-pass (LP) filtering in the space domain, followed by high-pass (HP) filtering in the time domain. Subsequently the atmospheric delay phases are separated from the results (Berardino et al. 2002) and we could finally generate a time series of deformation at

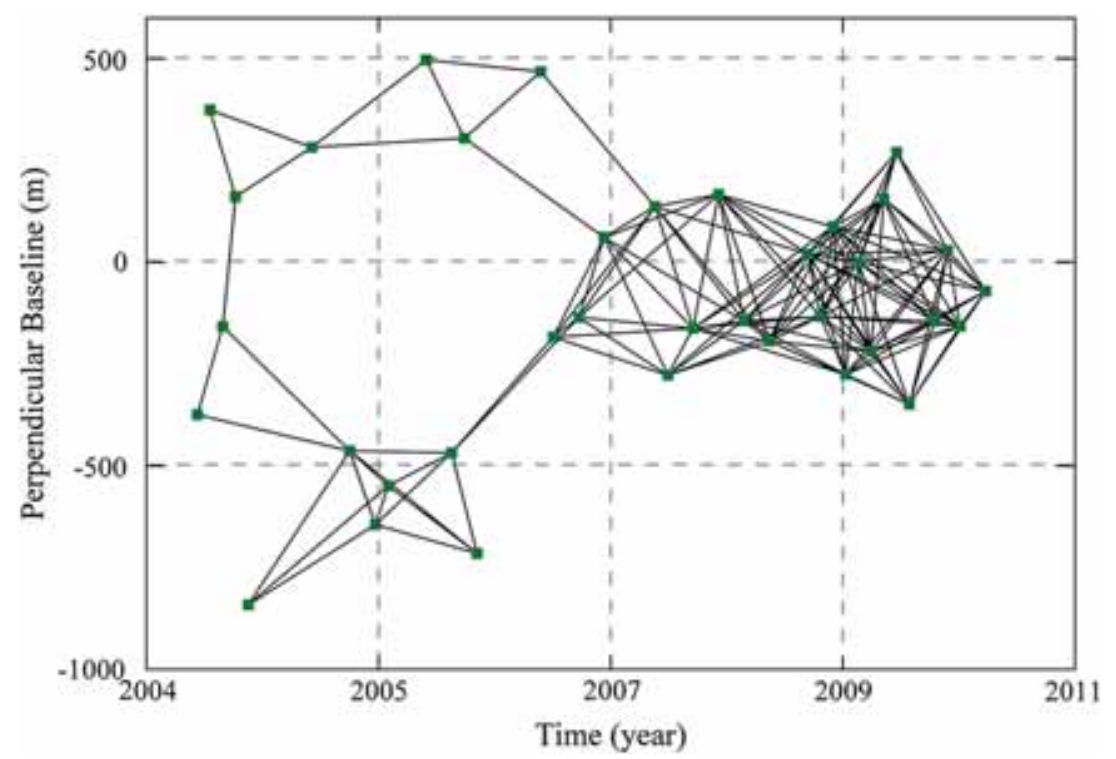

Figure 2. Relationship between the temporal and perpendicular baselines of the ENVISAT ASAR image pairs. 

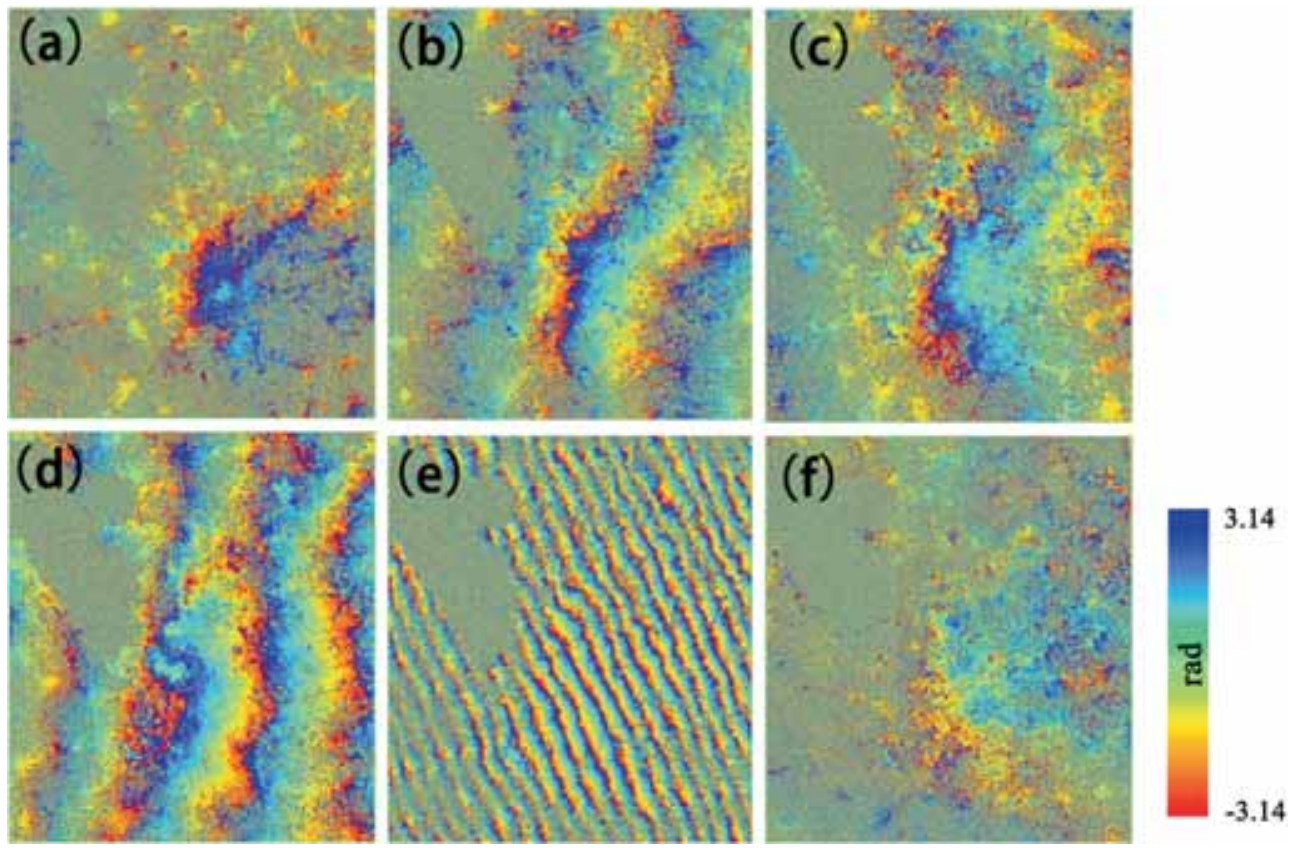

Figure 3. Interferograms constructed by the SBAS InSAR method. Interferogram generated with the images obtained on (a) 24 June 2004 and 29 July 2004, (b) 20 April 2006 and 25 January 2007, (c) 5 April 2007 and 6 December 2007 , (d) 25 December 2008 and 3 July 2008, (e) 18 June 2009 and 1 October 2009, and (f) 29 April 2010 and 27 August 2009.

each CP identified in the C-band ENVISAT ASAR images.

\section{Results}

The deformation map generated from the ENVISAT ASAR images is shown in figures 4 and 5. The total number of $\mathrm{CP}$ with small phases that were decorrelated over short time intervals was $6,809,836$. The CP measurement density was 3452 per $\mathrm{km}^{2}$. The high CP measurement density calculated by the InSAR SBAS method ensured that a detailed analysis could be conducted over a large area compared to GPS, levelling surveys and groundwater-level surveys (data for only five levelling surveys and six groundwater-level locations were available in this study; figure 1). From the results of ENNISAT ASAR SBAS InSAR processing (figure 4), noticeable land subsidence was displayed in the Wujin district and the central area of the Zhonglou district of Changzhou. However, land rebound was also observed in the districts of Xinbei, Tianning and in the eastern part of Zhonglou. The results indicate that the surface deformation in Changzhou was primarily within the range of -65 to $+20 \mathrm{~mm} / \mathrm{yr}$ in the LOS direction (figure 4). The deformation map also shows the accumulated

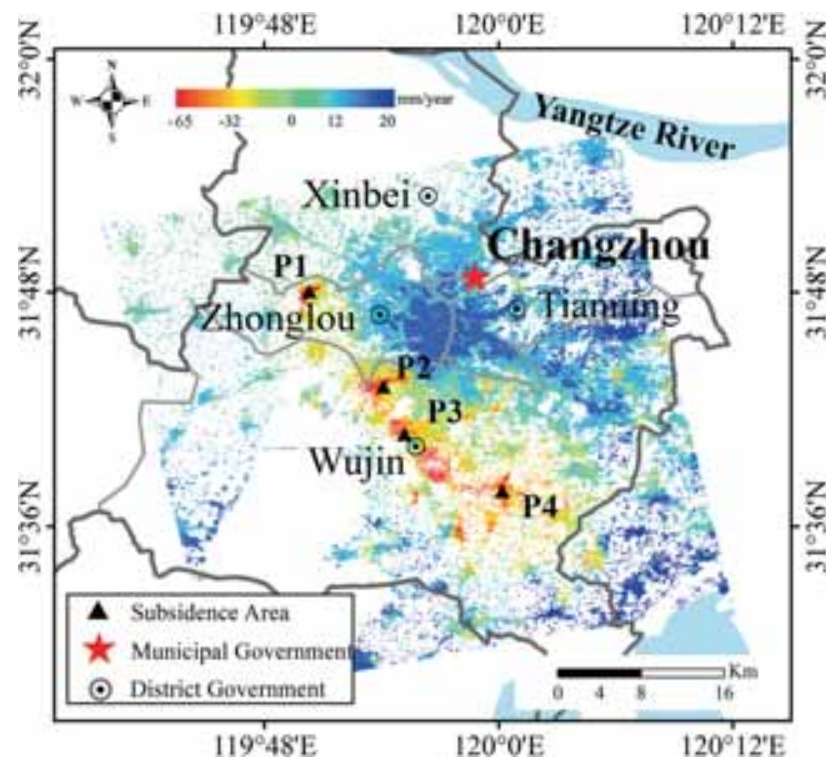

Figure 4. Deformation rates projected onto the LOS direction for the ENVISAT ASAR data at the selected study area. The black triangle represents the most serious subsidence area.

vertical surface deformation with respect to the image acquired from the first SAR image (20 May 2004) (figure 5). The accumulated vertical deformation from 2004 to 2010 in Changzhou ranged from -0.33 to $0.13 \mathrm{~m}$ (figure $5 \mathrm{~d}$ ). 

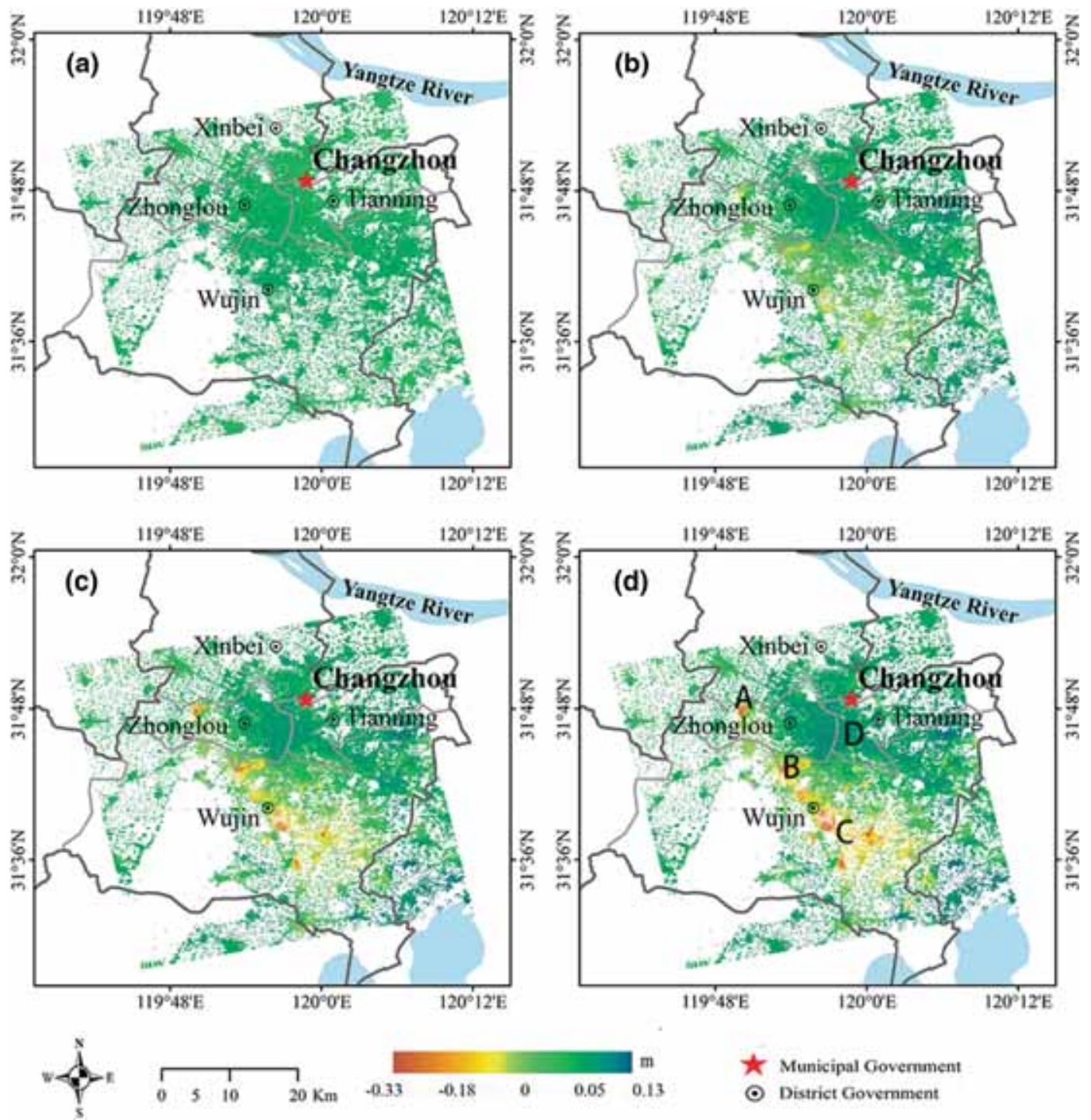

丸 Municipal Government

(-) District Govemment

Figure 5. Time series of accumulated vertical deformation values calculated from ENVISAT ASAR SBAS InSAR processing up to 20 May 2004: (a) 24 June 2004; (b) 21 December 2006; (c) 25 December 2008; and (d) 29 April 2010.

Because SBAS InSAR processing has advantages in estimating the vertical deformation between two particular acquisition dates, we calculated the cumulative deformations of 24 June 2004, 21 December 2006, 25 December 2008 and 29 April 2010 to 20 May 2004, respectively (figure 5). The yellow-coloured regions in figure 5 denote land subsidence and the dark yellow colour represents maximum subsidence. Between 24 June 2004 and 20 May 2004, no subsidence regions were observed (figure 5a). Between 21 December 2006 and 20 May 2004, some subsidence regions had begun to appear in region $\mathrm{C}$ in the Wujin district (figure 5b). Between 25 December 2008 and 20 May 2004, the subsidence regions expanded, particularly in Wujin district (figure 5c). By 29 April 2010, the area with accumulated subsidence values below $-8 \mathrm{~cm}$ had reached as much as $46.97 \mathrm{~km}^{2}$ (figure $5 \mathrm{~d}$ ). The subsidence in regions A-C (marked in figure 5d) grew quickly and reached their maximum subsidence during 2004 and 2010. The maximum subsidence $(-0.33 \mathrm{~m})$ occurred in region $\mathrm{C}$ which is located in the industrial park of Wujin district. In contrast to regions $\mathrm{A}-\mathrm{C}$, region $\mathrm{D}$ which is located in Tianning and the eastern portion of the Zhonglou district, experienced land rebound. The maximum rebound values reached as high as $0.13 \mathrm{~m}$ over $6 \mathrm{yr}$.

Several researchers have suggested that land subsidence in some areas of Changzhou city should be caused by two important factors in the process of urbanisation: overexploitation of groundwater and soil consolidation (Zhang et al. 2007; Shi et al. 
(a) Time-series subsidence for point P1 to P4

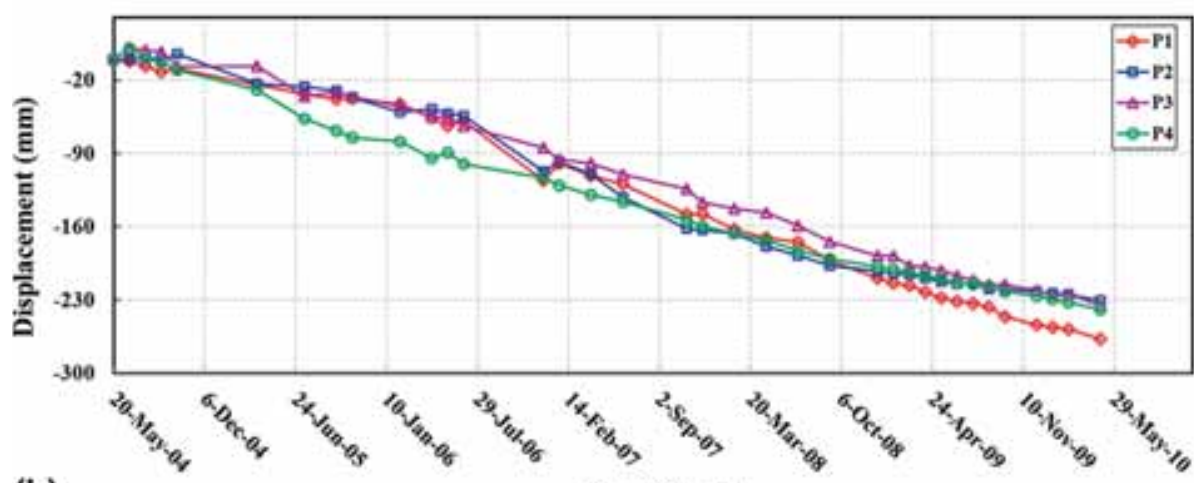

(b)

Time $(\mathbf{d} / \mathbf{m} / \mathbf{y})$

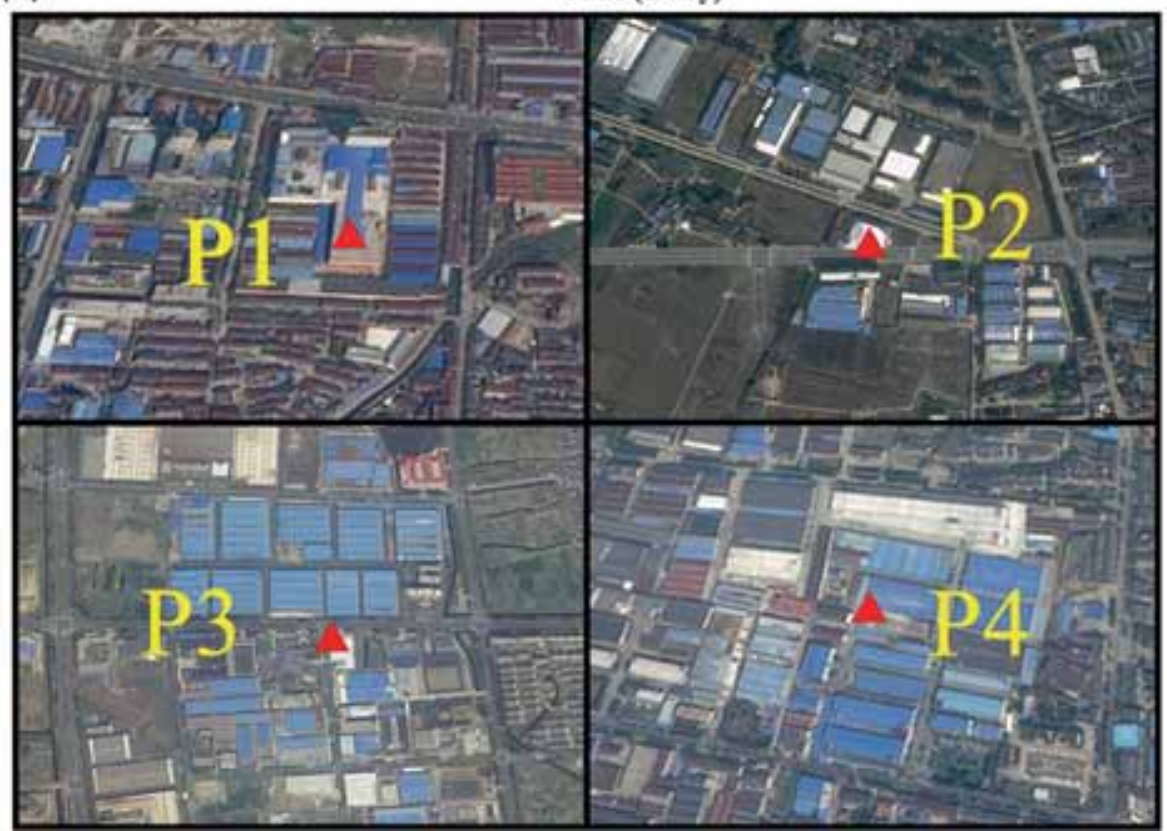

Figure 6. (a) Deformation history (LOS direction) of four points (P1-P4) in the subsidence funnel marked in figure 4 and (b) distributions of $\mathrm{P} 1-\mathrm{P} 4$.

2008; Xu et al. 2012). Extracted groundwater is used mainly for industry, residential and agriculture (e.g., industrial production, the public water system and agricultural irrigation, respectively). Construction of infrastructure such as industrial, residential and commercial buildings increased the surface load, leading to soil consolidation and, eventually, contributing to land subsidence. The InSAR results reveal that serious land subsidence occurred mostly in the industrial parks where the economy developed rapidly, where massive amounts of groundwater may be utilised for industrial purposes, and where many buildings were constructed. To obtain more detailed information about land deformation in Changzhou city, the large subsidence areas are presented as overlays on Bing Map (figure 6b). The buildings with white or blue roofs are related to industrial land use. It can be observed that the four large subsidence regions (around points $\mathrm{P} 1-\mathrm{P} 4$ in figure 4) are located in the industrial area (figure 6b). It is worth noting that land use around P1 included a mixture of residential (the high density distribution of red roofs in figure $6 \mathrm{~b}$ ) and industrial. The deformation history for points $\mathrm{P} 1-\mathrm{P} 4$ is shown in figure 6(a). The cumulative land deformation at points $\mathrm{P} 1-\mathrm{P} 4$ is $-267,-230,-235$ and $-239 \mathrm{~mm}$, respectively. The variation trends among these four points may suggest that the subsidence in these areas will last for a long time. The subsidence might be caused by the excessive groundwater extraction for industrial and residential purposes. However, because most subsidence regions are found around industrial zones with large buildings, it is likely that soil 
consolidation caused by surficial loading might also have played an important role in accelerating land subsidence.

\section{Discussion}

\subsection{Comparison between the InSAR and levelling measurements}

To assess the InSAR measurements, the InSARderived subsidence values were compared with the levelling observations. Because the centres of InSAR pixels may not exactly overlap the locations of the levelling benchmarks, an arithmetic mean method was used. First, we selected all InSAR pixels whose centres were within $100 \mathrm{~m}$ of the benchmarks. Second, we calculated the average displacement values from the selected InSAR pixels. The calculated mean values were taken as the InSAR measurements at the positions of the levelling benchmarks. Finally, the InSAR and levelling measurements were compared. The results are shown in figure 7 . The InSAR and levelling observations generally agreed well except for station II52. At station II52, the InSAR measurements remained stable after 2008, while the levelling measurements noticeably decreased. The difference between the InSAR and levelling measurements were likely caused by the following factors: (i) the InSAR measurements were the average of all pixels within a 100-m range around the benchmarks; (ii) each InSAR measurement was the average of
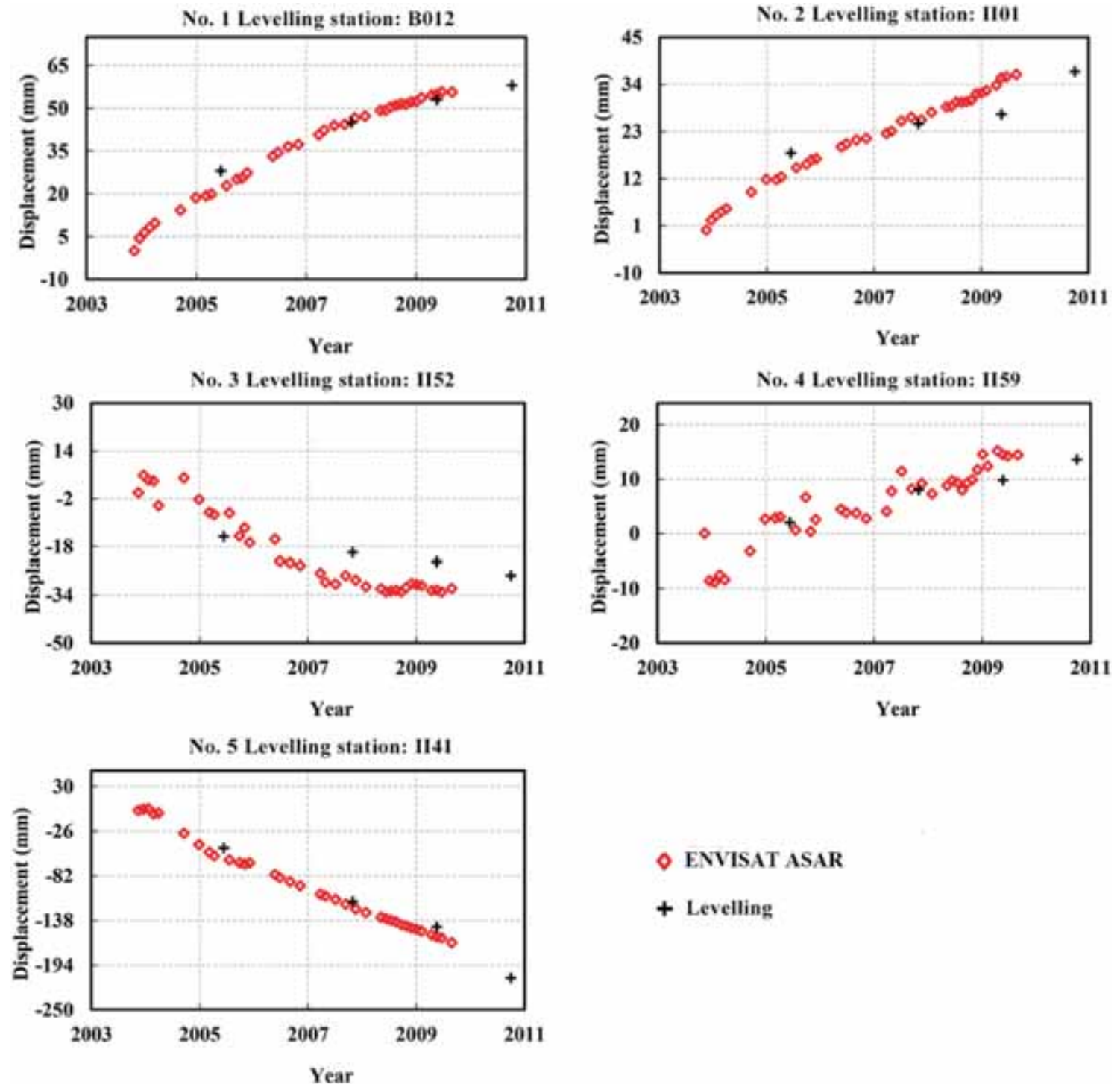

Levelling

Figure 7. Time series of subsidence from InSAR and levelling measurements at the five levelling benchmarks marked in figure 1 . 
the entire pixel scale while each levelling measurement was at the point scale and (iii) the errors in the InSAR and levelling measurements themselves may contribute to the differences.

From the InSAR-measured deformation history of the five levelling benchmarks shown in figure 7, we found that three of them (B012, II01 and II141) showed almost linear deformation over time; however, the deformation at stations II59 and II52 were nonlinear with time. This phenomenon may be related to the changes in the groundwater table. The two benchmarks (B52 and II141) which were located in the industrial parks in Wujin district (figure 1) experienced continuous land subsidence between 2004 and 2010. We speculated this phenomenon was closely related to groundwater exploitation without the permission of the local government in the industrial area, because of the government's regulation of groundwater here being relatively weaker compared to Xinbei, Zhonglou and Tianning districts. The other two benchmarks (II59 and II01), which were located in central urban districts, experienced an uplift due to land rebound - possibly caused by groundwater recharge after the policy limiting groundwater extraction was instituted in the 1990s ( $\mathrm{Hu} 2011)$.

The comparison between the InSAR and levelling measurements were in good agreement, with a correlation coefficient of 0.98 , suggesting that the deformation rates in Changzhou measured by these two methods were significantly correlated (figure 8). The standard deviation of the deformation rate between the two data sets was $+18 \mathrm{~mm} / \mathrm{yr}$. The comparison results indicate that the InSAR displacement time-series measurements agreed reasonably well with the ground truth in measuring the surface deformation. Because the temporal resolution of the levelling surveys for this study was lower than that of the InSAR measurements, it was difficult to obtain more detailed information about land deformation in Changzhou from the levelling measurements. The InSAR measurements, with higher temporal resolution than the levelling surveys, were able to provide more comprehensive information about land deformation in the Changzhou area. This information is useful for exploring the cause of the settlements, managing groundwater exploitation and evaluating geological hazards. The comparison result between the InSAR measurement and levelling survey data suggest that a comprehensive application of these two measurements can provide detailed information about land deformation.

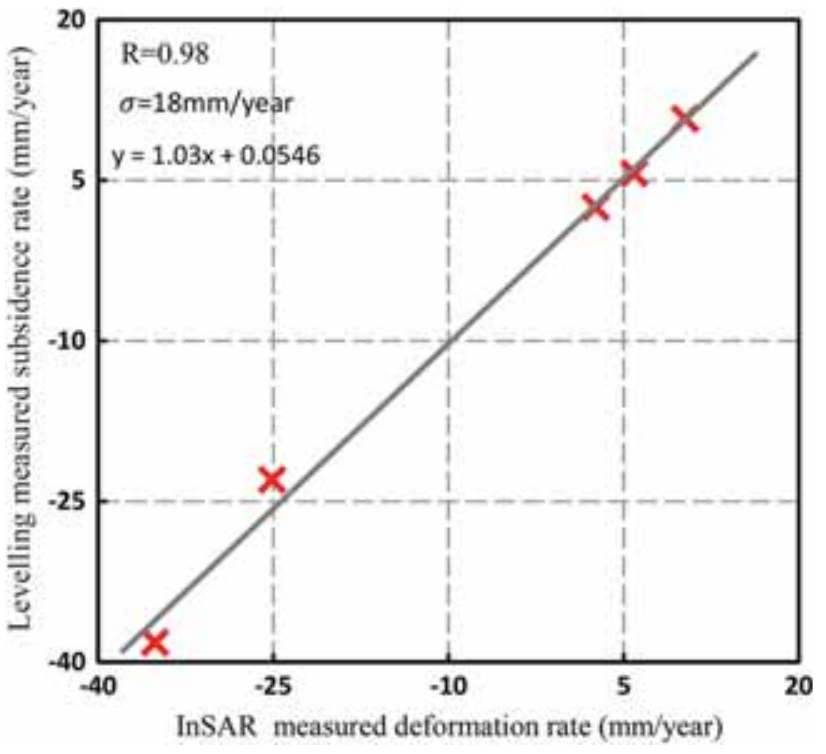

Figure 8. Comparison between the InSAR-derived and levelling-derived deformation rates at the levelling survey points shown in figure 6 .

\subsection{Correlation between land subsidence and groundwater}

According to the historical levelling survey data, land subsidence in Changzhou began in the 1970s and reached $50.63 \mathrm{~mm} / \mathrm{yr}$ between 1979 and 1983; the maximal subsidence reached approximately 100 mm (Hu 2011). Between 1984 and 1991, the average subsidence rate was $40-50 \mathrm{~mm} / \mathrm{yr}$, leading to a maximal cumulative subsidence of $949 \mathrm{~mm}$ in some of the central urban areas (Hu 2011). The average subsidence rate remained at approximately $40 \mathrm{~mm} / \mathrm{yr}$ between 1993 and 1998 ( $\mathrm{Hu}$ 2011). Since 1996, the government has limited groundwater withdrawal (Zhang et al. 2007, 2010; Shi et al. 2008; Wang et al. 2009), and land subsidence in Changzhou has slowed down. Since 2000, the observed subsidence rate has been approximately 25 mm/yr (Hu 2011). After 2004, except for the eastern part of Changzhou, land subsidence had been effectively curbed, and a slight rebound began to occur in some areas. The rebound area gradually expanded. By 2007, land subsidence in urban areas had been essentially stopped ( $\mathrm{Hu}$ 2011). To understand the influence of groundwater table variations on ground surface deformation after 2004, the deformation values obtained from the InSAR measurement were analysed in comparison with the changes in the groundwater table at six water wells (figure 1). The procedures discussed in section 5.1 are also used to match the 

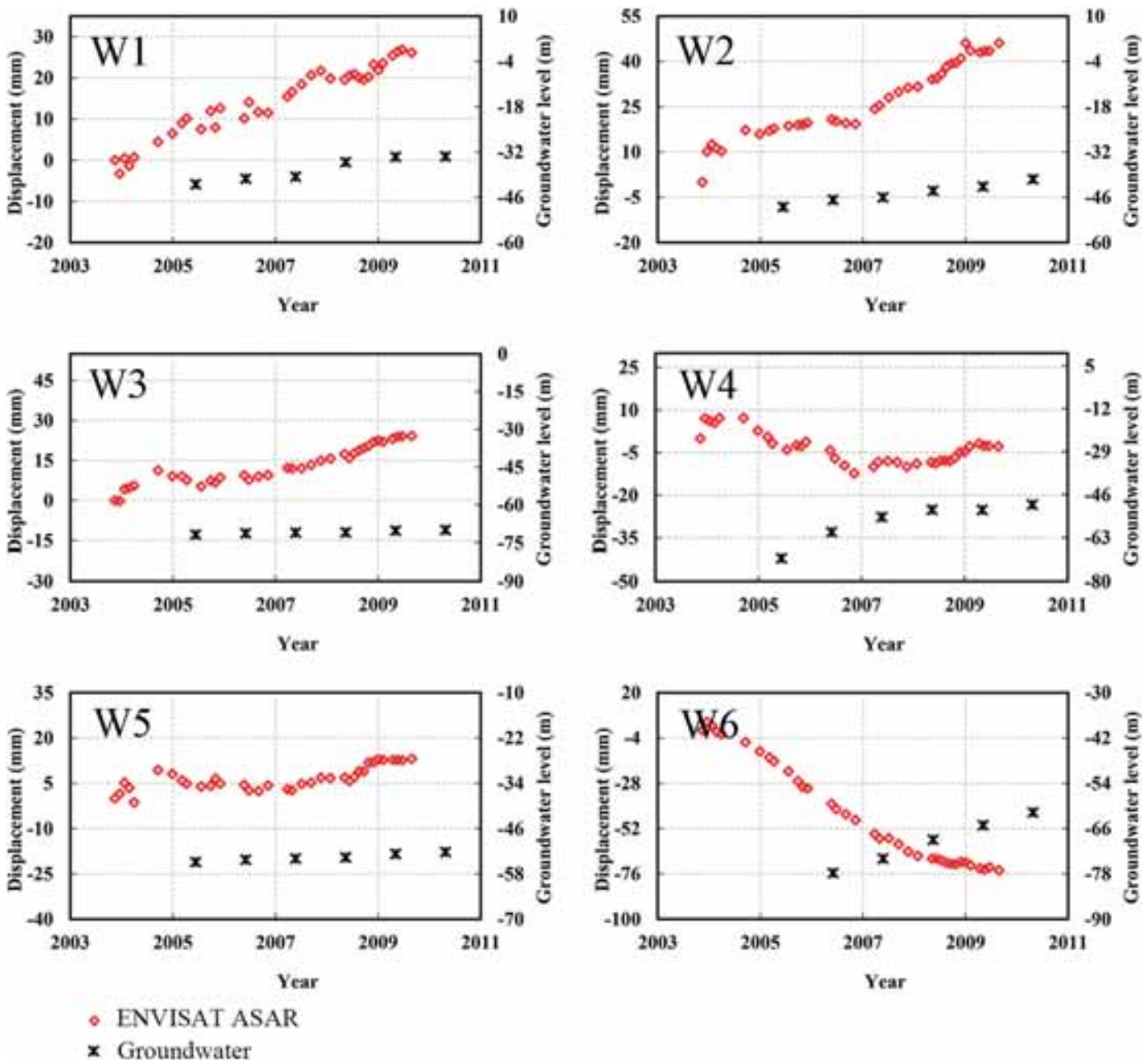

Figure 9. Groundwater table level and land deformation from 2006 to 2012 at groundwater wells in Changzhou. Stations W1-W6 are the water wells marked in figure 1.

InSAR pixels to the locations of these six water wells.

Land surface rebound was found at the groundwater well stations W1-W3 and W5 as the groundwater table increased (figure 9). These groundwater stations were located within the main urban region of Changzhou (in Xinbei, Tianning and the eastern part of the Zhonglou district). The land surface uplift in this region was due to the strict regulatory measures put in place to prohibit the exploitation of groundwater (Xu et al. 2015). At station $\mathrm{W} 4$, the InSAR measurements were consistent with the change in the groundwater table after 2007. However, the land subsidence measurements were not in synchronisation with the groundwater table changes at the groundwater well station W6, located in Wujin district: the groundwater table rose, but land subsidence continued. To better identify the influence of groundwater change on the ground surface deformation, a correlation analysis between the groundwater table values and surface deformations was performed. Positive correlation coefficients of $0.90,0.86,0.97$ and 0.96 were observed at well stations W1-W3 and W5, respectively, while a lower correlation coefficient of 0.5 was observed at stations W4. The lower correlation coefficient of W4 was caused by the rebound of ground surface in November 2007. However, at well W6, a negative correlation coefficient of -0.96 was found. These results suggest that groundwater table changes had mixed effects on surface deformation during 2004 and 2010. According to relevant studies, the land subsidence in some area of Changzhou city has been effectively controlled and the land deformation showed an upward trend since 2004 (Zhang et al. 2010; Hu 2011). These areas include the Xinbei district, the eastern part of the Zhonglou district (where well W2 is located), the western part of the Tianning district (where wells W1, W3 and W5 are located) (Hu 2011). 
The research studies by Xu et al. (2011a,b) indicated that the hysteresis phenomena exist in the consolidation of strata during the process of the groundwater table variation and the state of consolidation of strata plays a very important role in land subsidence. As the wells W4 and W6 were located in the settlement area from 2001 to 2004 (Hu 2011), it was indicated that the consolidation of the strata around the wells W4 (before November 2007) and W6 (from May 2004 to April 2010) had not been completed after the exploitation of groundwater was prohibited. The strata in this area were still in a state of compression, though the groundwater table rose (Zhang et al. 2010; Xu et al. 2011a, b). This process will continue until the consolidation of the strata is completed. From our InSAR result in W4, we deduced that, in November 2007, this region completed the strata consolidation, and expressed a subsequent trend of surface rebound. It is also essential to notice that creep deformation played an important role during the consolidation of the strata, especially at the stage of groundwater recovery under this geological condition ( $\mathrm{Xu}$ et al. 2008; Wang et al. 2013).

In contrast, the wells W1-W3 and W5 were not in the subsidence area after 2004 which may indicate that the consolidation of the strata around these wells was completed before 2004. So, in the following time, the land surface rebound with the groundwater table rise. In W4, we speculate that the consolidation of the strata was completed after November 2007 from the InSAR result. So, the land deformation of W4 expressed a trend of land rebound with the groundwater level rising.

Other factors such as consolidation caused by surface loading and other geologic condition may also contribute to land deformation (Wang et al. 2009; Zhang et al. 2010; $\mathrm{Hu}$ 2011). Moreover, because we lack the groundwater table data in the areas with large subsidence (including the Wujin district and the centre part of the Zhonglou district), a detailed analysis concerning the relation between subsidence and groundwater exploitation in these areas is not possible in this section.

\section{Conclusions}

Long-term land displacement in the Changzhou city was mapped based on time-series interferograms in the C-bands using the SBAS InSAR technique. To assess the InSAR measurements and identify the cause of deformation, levelling observations and groundwater table measurements within the second confined aquifer were analysed along with the InSAR results. We concluded that: (i) large land subsidence regions were found in the Wujin and Zhonglou districts. The maximum subsidence rate reached $-65 \mathrm{~mm} / \mathrm{yr}$ along the LOS direction. The accumulated vertical deformation from 2004 to 2010 in Changzhou ranged from -0.33 to $+0.13 \mathrm{~m}$. The results from ENVISAT ASAR images showed that the subsidence rate was steady over Xinbei, Tianning and the eastern part of the Zhonglou district. By overlaying the large subsidence areas on a Bing Map, it is indicated that the subsidence in these regions might be caused by groundwater exploitation and soil consolidation due to the surface loads from artificial structures; (ii) a comparison between the InSAR and levelling measurements demonstrated that the two measurements are well correlated with a correlation coefficient of 0.98 and a standard deviation of $18 \mathrm{~mm}$. This comparison shows that the InSAR measurements agreed well with the ground truth data and can be used to provide deformation information over a large area around Changzhou city than the small ground levelling network; (iii) the correlation analysis between land deformation and the groundwater table at groundwater well stations suggested that changes in the groundwater table had mixed effects on surface deformation during 2006 and 2012. A sharp rise in the groundwater level can cause land rebound (e.g., stations W1-W3, W5 and W4 (after November 2007)). However, in W6 and W4 (before November 2007), land subsidence was observed along with simultaneous increases in water table levels (W6). This phenomenon was caused by the status of consolidation of the strata, especially the occurrence of creep features in the saturated sand layer.

Our study indicated that the InSAR timeseries analysis methods such as SBAS were useful in the long-term monitoring of subsidence or uplift in Changzhou city during its rapid urbanisation. However, we only analysed the relationship between the groundwater table and land subsidence/uplift and not the effects of artificial infrastructures and other natural factors. In future work, we plan to focus on investigating more parameters related to ground deformation to study land deformation in the Changzhou area. 


\section{Acknowledgements}

This work was supported by the Key Technology R\&D Program of Jiangsu Province (BE2013702), program of the National Nature Science Foundation of China (Nos. 41371391, 41501497 and 41601497), Jiangsu Graduate Student Research Innovative Projects (KYZZ16_0046).

\section{References}

Abidin H Z, Andreas H, Gumilar I, Sidiq T P and Fukuda Y 2013 Land subsidence in coastal city of Semarang (Indonesia): Characteristics, impacts and causes; Geomat. Nat. Hazards Risk 4(3) 226-240, https://doi.org/ 10.1080/19475705.2012.692336.

Akcin H, Kutoglu H S, Kemaldere H, Deguchi T and Koksal E 2010 Monitoring subsidence effects in the urban area of Zonguldak Hardcoal Basin of Turkey by InSAR-GIS integration; Nat. Hazards Earth Syst. 10(9) 1807-1814, https://doi.org/10.5194/nhess-10-1807-2010.

Baek J, Kim S W, Park H J, Jung H S, Kim K D and Kim J W 2008 Analysis of ground subsidence in coal mining area using SAR interferometry; Geo. Sci. J. 12(3) $277-$ 284, https://doi.org/10.1007/s12303-008-0028-3.

Berardino P, Fornaro G, Lanari R and Sansosti E 2002 A new algorithm for surface deformation monitoring based on small baseline differential SAR interferograms; IEEE Trans. Geosci. Remote Sens. 40(11) 2375-2383.

Brunori C, Bignami C, Albano M, Zucca F, Samsonov S, Groppelli G, Norini G, Saroli M and Stramondo S 2015 Land subsidence, ground fissures and buried faults: InSAR monitoring of Ciudad Guzmán (Jalisco, Mexico); Remote Sens-Basel. 7(7) 8610-8630, https://doi.org/10. $3390 /$ rs70708610.

Bürgmann R, Rosen P A and Fielding E J 2000 Synthetic aperture radar interferometry to measure earth's surface topography and its deformation; Ann. Rev. Earth Planet. Sci. 28 169-209.

Castellazzi P, Arroyo-Domínguez N, Martel R, Calderhead A I, Normand J C L, Gárfias J and Rivera A 2016 Land subsidence in major cities of Central Mexico: Interpreting InSAR-derived land subsidence mapping with hydrogeological data; Int. J. Appl. Earth Obs. 47 102-111, https:// doi.org/10.1016/j.jag.2015.12.002.

Chaussard E, Bürgmann R, Shirzaei M, Fielding E J and Baker B 2014 Predictability of hydraulic head changes and characterization of aquifer-system and fault properties from InSAR-derived ground deformation; J. Geophys. Res.-Sol. Ea. 119(8) 6572-6590, https://doi.org/ $10.1002 / 2014 \mathrm{jb} 011266$.

Conway B D 2015 Land subsidence and earth fissures in south-central and southern Arizona, USA; Hydrogeol. J. 24(3) 649-655, https://doi.org/10.1007/s10040-015-13 29-z.

Costantini M 1998 A novel phase unwrapping method based on network programming; IEEE Trans. Geosci. Remote Sens. 36(3) 813-821.
Curlander J C and Mcdonough R N 1991 Synthetic aperture radar: Systems and signal processing; John Wiley \& Sons, New Jersey.

Ding R, Xu J, Lin X and Xu K 2015 Monitoring of surface subsidence using PSInSAR with TerraSAR-X high resolution data; Remote Sens. Land Resour. 27(4) 158-164 (in Chinese).

Dong S, Samsonov S, Yin H, Ye S and Cao Y 2014 Timeseries analysis of subsidence associated with rapid urbanization in Shanghai, China measured with SBAS InSAR method; Environ. Earth Sci. 72(3) 677-691, https://doi. org/10.1007/s12665-013-2990-y.

Faunt C C, Sneed M, Traum J and Brandt J T 2015 Water availability and land subsidence in the Central Valley, California, USA; Hydrogeol. J. 24(3) 675-684, https://doi. org/10.1007/s10040-015-1339-x.

Ferretti A, Prati C and Rocca F 2000 Nonlinear subsidence rate estimation using permanent scatterers in differential SAR interferometry; IEEE Trans. Geosci. Remote Sens. 38(5) 2202-2212.

Ferretti A, Prati C and Rocca F 2001 Permanent scatterers in SAR interferometry; IEEE Trans. Geosci. Remote Sens. 39(1) 8-20.

Hallegatte S, Green C, Nicholls R J and Corfee-Morlot J 2013 Future flood losses in major coastal cities; Nat. Clim. Change 3(9) 802-806, https://doi.org/10.1038/ nclimate1979.

$\mathrm{Hu}$ J 2011 A study on the land subsidence effect after prohibiting extraction of groundwater in Suzhou-WuxiChanzghou Area; PhD Thesis, Nanjing University (in Chinese).

Hu J, Li Z W, Li J, Zhang L, Ding X L, Zhu J J and Sun Q 2014 3-D movement mapping of the alpine glacier in Qinghai-Tibetan Plateau by integrating D-InSAR, MAI and offset-tracking: Case study of the Dongkemadi Glacier; Global Planet. Change 118 62-68, https://doi. org/10.1016/j.gloplacha.2014.04.002.

Hwang C, Yang Y, Kao R, Han J, Shum C K, Galloway D L, Sneed M, Hung W and Cheng Yang Li F 2016 Time-varying land subsidence detected by radar altimetry: California, Taiwan and north China; Sci. Rep. 6(1), https://doi.org/10.1038/srep28160.

Kimura H and Todo M 1997 Baseline estimation using ground points for interferometric SAR; geoscience and remote sensing, 1997; In: IGARSS '97 - 1997 IEEE international remote sensing - A scientific vision for sustainable development, IEEE 2002(1) 442-444.

Kohlhase A O, Feigl K L and Massonnet D 2003 Applying differential InSAR to orbital dynamics: A new approach for estimating ERS trajectories; J. Geodesy $\mathbf{7 7 ( 9 )} 493$ 502.

Lanari R, Mora O, Manunta M and Mallorqui J J 2004 A small-baseline approach for investigating deformations on full-resolution differential SAR interferograms; IEEE Trans. Geosci. Remote Sens. 42(7) 1377-1386.

Lanari R, Casu F, Manzo M, Zeni G, Berardino P, Manunta $\mathrm{M}$ and Pepe A 2007 An overview of the small Baseline subset algorithm: A DInSAR technique for surface deformation analysis; Pure Appl. Geophys. 164(4) 637-661, https://doi.org/10.1007/s00024-007-0192-9.

Lauknes T R, Shanker A P, Dehls J F, Zebker H A, Henderson I H C and Larsen Y 2010 Detailed 
rockslide mapping in northern Norway with small baseline and persistent scatterer interferometric SAR time series methods; Remote Sens. Environ. 114(9) 20972109, https://doi.org/10.1016/j.rse.2010.04.015.

Lin $\mathrm{H}$ and Ke C 2016 Monitoring surface deformation in Changzhou city using COSMO-SkyMed data; Remote Sens. Technol. Appl. 31(3) 599-606 (in Chinese).

Ma F S, Yang Y S, Yuan R M, Yao B K and Guo J 2010 Effect of regional land subsidence on engineering structures: A case study of the $6 \mathrm{~km}$ long Su-tong Yantze River Bridge; Bull. Eng. Geol. Env. 70(3) 449-459, https://doi.org/10. 1007/s10064-010-0336-5.

Necsoiu M, Mcginnis R N and Hooper D M 2014 New insights on the Salmon Falls Creek Canyon landslide complex based on geomorphological analysis and multitemporal satellite InSAR techniques; Landslides 11(6) 11411153.

Notti D, Mateos R M, Monserrat O, Devanthéry N, Peinado T, Roldán F J, Fernández-Chacón F, Galve G P, Lamas F and Azañón J M 2016 Lithological control of land subsidence induced by groundwater withdrawal in new urban AREAS (Granada Basin, SE Spain). Multiband DInSAR monitoring; Hydrol. Process. 30(13) 2317-2331, https:// doi.org/10.1002/hyp.10793.

Rabus B, Eineder M, Roth A and Bamler R 2003 The shuttle radar topography mission - A new class of digital elevation models acquired by spaceborne radar; ISPRS J. Photogramm. 57(4) 241-262.

Shanker P, Casu F, Zebker H A and Lanari R 2011 Comparison of persistent scatterers and small baseline time-series InSAR results: A case study of the San Francisco bay area; IEEE Trans. Geosci. Remote Sens. 8(4) 592-596, https://doi.org/10.1109/LGRS.2010.2095829.

Shi X, Wu J, Ye S, Zhang Y, Xue Y, Wei Z, Li Q and Yu J 2008 Regional land subsidence simulation in Su-Xi-Chang area and Shanghai City, China; Eng. Geol. 100(1-2) 2742, https://doi.org/10.1016/j.enggeo.2008.02.011.

Usai S 2003 A least squares database approach for SAR interferometric data; IEEE Trans. Geosci. Remote Sens. 41(4) $753-760$.

Wang R, Xia Y, Grosser H, Wetzel H U, Kaufmann H and Zschau J 2004 The 2003 Bam (SE Iran) earthquake: Precise source parameters from satellite radar interferometry; Geophys. J. Int. 159(3) 917-922.

Wang G Y, You G, Shi B, Yu J and Tuck M 2009 Long-term land subsidence and strata compression in Changzhou, China; Eng. Geol. 104(1) 109-118.

Wang G, Xie M, Chai X, Wang L and Dong C 2012 D-InSARbased landslide location and monitoring at Wudongde hydropower reservoir in China; Environ. Earth Sci. 69(8) 2763-2777, https://doi.org/10.1007/s12665-012-2097-x.

Wang F, Miao L and Lu W 2013 Sand creep as a factor in land subsidence during groundwater level recovery in the southern Yangtze river delta, China; Bull. Eng. Geol. Environ. 72(3-4) 273-283, https://doi.org/ 10.1007/s10064-013-0474-7.

Xie Y, Cao N and Xu L 2009 Land subsidence monitoring in Changzhou; City Urban Geotech. Invest. Surv. 6(3) 103105 (in Chinese).

Xu H, Zhou Z and Gao Z 2011a Experimental study on coefficient of consolidation of land subsidence; Chinese J. Geotech. Eng. 33(12) 1969-1973 (in Chinese).

$\mathrm{Xu} \mathrm{H}$, Zhou Z and Gao Z 2011b Experimental research of hysteresus effect of land subsidence caused by water releasing; Chinese J. Rock Mech. Eng. 30(2) 3595-3601 (in Chinese).

Xu Y S, Ma L, Du Y J and Shen S L 2012 Analysis of urbanisation-induced land subsidence in Shanghai; Nat. Hazards 63(2) 1255-1267, https://doi.org/10.1007/ s11069-012-0220-7.

Xu Y S, Yuan Y, Shen S L, Yin Z Y, Wu H N and Ma L 2015 Investigation into subsidence hazards due to groundwater pumping from Aquifer II in Changzhou, China; Nat. Hazards 78(1) 281-296, https://doi.org/10.1007/ s11069-015-1714-X.

Xue Y, Wu J, Zhang Y, Ye S, Wei Z, Li Q and Jun Y 2008 Simulation of the regional land subsidence at south of Yangtze river delta; Sci. China Press 38(4) 477-492.

Zhang A M 2016 Ground subsidence detection of Wujin Based on PS-InSAR; Mod. Surv. Mapp. 39(2) 1-4 (in Chinese).

Zhang Y, Xue Y Q, Wu J C, Ye S J, Wei Z X, Li Q F and Yu J 2007 Characteristics of aquifer system deformation in the Southern Yangtse Delta, China; Eng. Geol. 90(3-4) 160-173, https://doi.org/10.1016/j.enggeo.2007. 01.004 .

Zhang Y, Xue Y Q, Wu J C, Shi X Q and Yu J 2010 Excessive groundwater withdrawal and resultant land subsidence in the Su-Xi-Chang area, China; Environ. Earth Sci. 61(6) 1135-1143, https://doi.org/10.1007/s12665-009-0433-6.

Zhao C, Lu Z, Zhang Q and Fuente J D L 2012 Large-area landslide detection and monitoring with ALOS/PALSAR imagery data over Northern California and Southern Oregon, USA; Remote Sens. Environ. 124(9) 348-359, https://doi.org/10.1016/j.rse.2012.05.025.

Zhu W and Liu F 2007 Surface subsidence observation and results analysis of Changzhou, China; Eng. Surv. Mapp. 16(6) 54-57 (in Chinese). 